\title{
Rising trends of cesarean section worldwide: a systematic review
}

\begin{abstract}
Background: Cesarean section (CS) is the most common surgery performed around the world. The World Health Organization (WHO) suggests a cesarean rate from $5 \%$ to $15 \%$, but the worldwide percentage is higher. Objective: The aim of this study was to conduct a systematic review to analyze if there are some factors associated with the increment of CS rate like public or private hospitals, mothers' age, CS indication, educational level and socioeconomic status.

Methods: A systematic review was conducted using PubMed, EBSCO and Medscape databases to identify studies published from 2000 to 2015.

Findings: A total 22 articles were included from eighteen different countries. All of them showed an overwhelming prevalence of CS, compared with the stipulated by the WHO, with a mean of $45.2 \%$ of CS worldwide. The rate of cesarean delivery was higher at the private hospitals than in the public ones.

Conclusion: It is necessary to regulate the quantity of CS performed in hospitals, to reduce health costs and maternal and fetal risks. CS prevalence is markedly high around the world, especially in the private sector, that clearly demonstrates that there are other factors involved in this group of users.
\end{abstract}

Volume 3 Issue 2 - 2015

\author{
Elena Soto Vega, ${ }^{1,2}$ Casco S, ${ }^{3}$ Chamizo K, ${ }^{3}$ \\ Flores-Hernÿndez D, ${ }^{3}$ Landini V, ${ }^{3}$ Guillén- \\ Florez ${ }^{3}$ \\ 'Departamento de Ciencias de la Salud, Universidad Popular \\ Autónoma del Estado de Puebla, Mexico \\ ${ }^{2}$ Centro de Investigación Oncológica, Una Nueva Esperanza- \\ UPAEP, Mexico \\ ${ }^{3}$ Facultad de Medicina, Universidad Popular Autónoma del \\ Estado de Puebla, Mexico
}

Correspondence: Elena Soto Vega, Universidad Popular Aut noma del Estado de Puebla, 2 I sur I I 03 Col. Barrio de Santiago, C.P. 724I 0 Puebla, Puebla, México, Tel 01 (222) 2-29-94-00 ext: 7I40, Email elena.soto0I@upaep.mx

Received: October 26, 2015 | Published: November 6, 2015

\section{Introduction}

The Cesarean section (CS) has been increasing worldwide. CS is the most common abdominal surgery procedure, performed around the world, explaining its high prevalence worldwide. The World Health Organization (WHO) suggests a cesarean rate between 5\% and 15\%; a rate above $15 \%$ implies an unnecessary and unjustified use of surgical delivery, whereas a rate below 5\% may be related to the population's lack of access to medical technology. ${ }^{1,2}$ Some factors that contribute to the increased use of CS are: the improvement of surgical and anesthetic techniques, reduction of the postoperative complications and the perception of greater safety during the procedure.

CS rate has become more prevalent over the years, without medical justification and regardless the risk that it may bring to mothers and children born by CS. There are several adverse effects that may affect the mother, which include maternal death, the greater number of hospital remissions and increases the risk in future pregnancies for placenta previa. Respiratory distress syndrome is the only adverse outcome well documented in babies born by $\mathrm{CS}^{3-5}$ In addition, there are chronic diseases that occur more frequently in children born by CS

CS remains the most profitable for physicians and hospitals, and for the mother is more convenient to set up the surgery date than to wait for an unpredictable onset of labor. However, in a normal pregnancy, CS has eight fold higher mortality than vaginal delivery, in addition to 8-12 times higher morbidity. Has been an alarming increase of the worldwide CS rate in the last decade, CS prevalence had an estimate, until 2010, of 17.6\%. The World Health Organization (WHO) yielded an estimate of CS prevalence by continent; $36 \%$ in America, $23 \%$ in Europe, $9 \%$ in Asia and 4\% in Africa. ${ }^{6}$ Nevertheless, there is not a world research on cesarean prevalence and the factors that contribute to this health problem.
The woman's motivation for the choice of CS includes: fear of vaginal delivery, preservation of coital function, relief from the pain of labor, and to obtain a tubal ligation.?

The aim of this systematic review is to determine and analyze the prevalence and frequency of CS in private hospitals in comparison to the public health systems in different countries of the world. The specific objectives of the study were to determine the relation between age, cesarean indication, educational level and socioeconomic level with the election of a cesarean delivery.

\section{Methods}

\section{Search strategy}

A literature search was conducted from 2000 to 2015, from different languages, using the keywords of cesarean or caesarean section and prevalence. A combination of these keywords was used in subject headings including the advanced search criteria, with the filter of year, studies in humans, and full text articles. Articles were acknowledged via extensive electronic searches of the standardized computer database, including PubMed, EBSCO and Medscape. The main goal was to identify relevant studies describing the prevalence of $\mathrm{CS}$ in the public and private system. For articles with same population, resources or overlapping datasets, the largest or most recent one was included.

\section{Study selection}

The inclusion criteria were original research articles that included the cesarean/caesarean section prevalence in public and private hospitals. The search of standardized computer databases yielded 6420 articles. Sixty articles were retained for full review (Figure 1). We eliminated studies if the results didn't include the difference between public and private hospitals, or did not establish the cesarean rate percentage. 


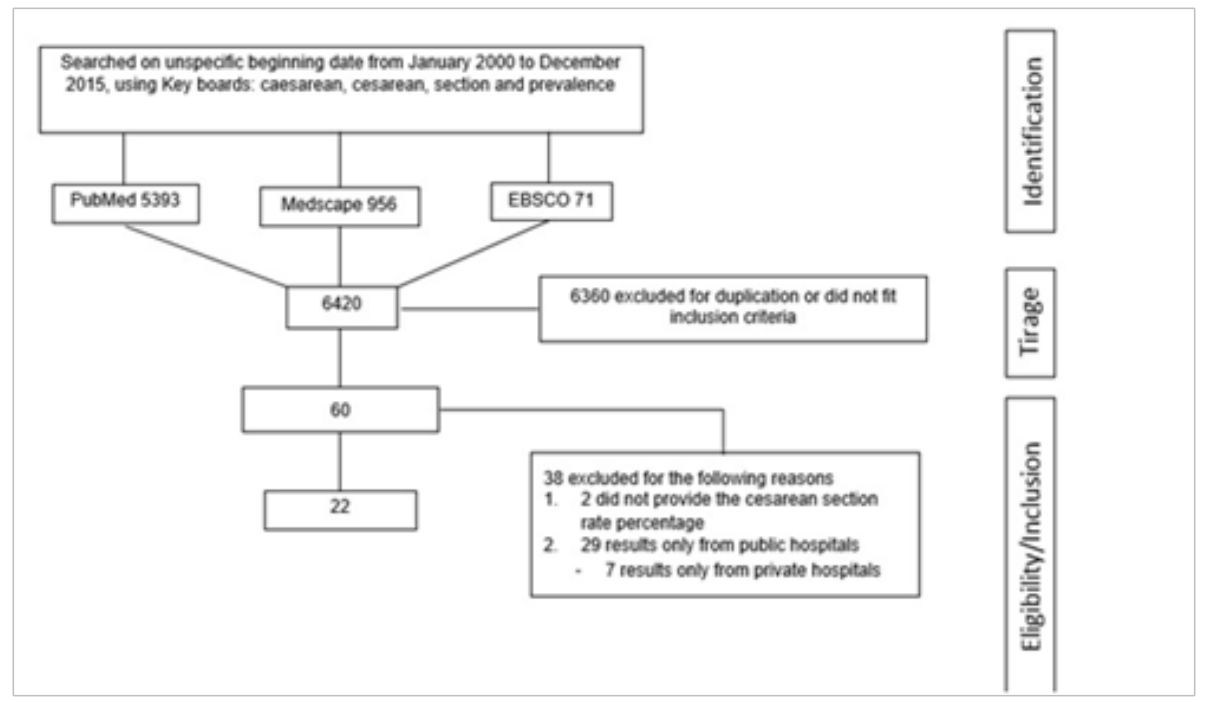

Figure I Flowchart portraying the search strategy and details of inclusion and exclusion.

\section{Identified studies and handling of missing data}

As shown in Figure 1 the flowchart portraying the search strategy and details of inclusion and exclusion. For the 60 articles preserved full review, studies were used to systematically assess study bias, and each author independently evaluated the studies. Reference lists of each of the 22 retained articles for full review were examined, but no additional articles were identified that meet our inclusion criteria. If a study failed to report any of the variables, this was classified as "not reported". It was then analyzed the results comparing only the available data.

All potential differences in interpretation between the reviewers were discussed, to ensure that all the articles reviewed present a satisfactory level of evidence.

Our systematic review included the following questions in relation to the factors leading the increase of CS prevalence, in public and private hospitals.

a. What is the CS prevalence between public and private hospitals?

b. What is the age range among women having CS?

c. Which are the major indications for CS?

d. The educational level is an important factor for the CS decision?

e. Does socioeconomic level influence in the higher prevalence of CS?

All articles provided the percentage of CS prevalence in public and private hospitals. However, some of the articles contained the information layered by years; subsequently it was necessary to make the estimate of the general prevalence. Data of the articles were organized in a table to summarize the information obtained in each reviewed articles, as well as we include a table of the relationship between public and private hospitals cesarean section prevalence. In those articles in which the variables studied were presented in different ranges, they were unifying, in order to analyze them.

\section{Statistical analysis}

The data analysis was performed using the statistical package Graph Pad version 4.00 for windows, San Diego, CA. Descriptive analysis was performed, including frequencies, percentages, means, and standard deviations.

\section{Results}

A systematic search of PubMed, Medscape and EBSCO yielded 5393, 956 and 71 results respectively. After removing duplicates or those that did not fit the inclusion criteria, 60 eligible studies were screened, but 38 were excluded because do not show the cesarean rate or the result were only of public or private system.

\section{Characteristics of studies reviewed}

Twenty two appropriate articles collect the search and inclusion criteria; represent 1, 713094 pregnant women, from 18 countries in 4 continents. Because all studies were observational, risk for bias was similar through every study. Nine studies derived data from a state or regional cohort and twelve national samples (Table 1). The most common covariates in study analyses were maternal age, parity, cesarean indication motive, socio-demographic situation and place of residence

\section{What is the CS prevalence between public and private hospitals?}

Practically, the worldwide health system is divided in public and private facilities; with specific characteristics according to the country, generally the health costs are higher in the private system than in public. The majority of the studies included in this review reported CS prevalence around 30 to $40 \%$, the mean of all the studies was $42.5 \%$. As shown in Table 2, the average cesarean section rate across the studies reviewed exceeded the WHO recommendation, the studies that were closer to the WHO recommendation were Egypt ${ }^{8}$ with a CS prevalence of $20.9 \%$ and Ethiopia with $18 \%{ }^{9}$ There are also some studies that showed exaggerated numbers like the data presented by Ghotbi et al. ${ }^{10}$ where they showed a rate of $83.5 \%$ of CS in Iran; in addition it is also the country with the most elevated rates in both sectors: $91.9 \%$ and $78.5 \%$ respectively. ${ }^{10}$ 
The analysis realized according to the health system of attention is very interesting; it shows that worldwide in the private sector the mean is $65.84 \%$ while in public the rate is $33.99 \%$. It is remarkable the CS rate in the private sector in countries like Iran, Brazil and México reaching $91.9,85.8$, and $85.6 \%$, respectively, ${ }^{10,11}$ also the same countries have the highest rate of CS in public sector being $78.5,71.0$ and $47.8 \%$ respectively. ${ }^{12}$ Despite the apparently favorable comparison, between the public and private system, the CS prevalence at the public system is still high, it is twice than the $15 \%$ suggested by WHO.

The statistical analysis shows that there was an extremely statistically significant difference $(p \leq 0.0001)$ when the general CS rate was compared versus the private hospital, and also when private hospitals were compared versus public hospitals. There was no statistical difference between general CS rate and public hospitals. $(\mathrm{p}=0.0932)$

\section{What is the age range among women having CS?}

In the analysis of the articles included in this systematic review it was observed a clear relationship between the age and method of delivery, among women, it is interesting that almost all the authors mention a correlation between age and CS, but less than half of them showed an analysis to correlate age and CS prevalence. Only eleven studies established a relationship between age range and CS prevalence, with an $\mathrm{N}$ of 341,873 . It was observed that the majority of cesarean deliveries were in women between the 30 and 40 years old (Table 3). It is interesting the results observed by Rebelo, Redondo and Soto-Vega where CS reaches more than $60 \%$ of the deliveries procedures after the 30 years old, reaching $82.5 \%$ of women older than 30 in México. ${ }^{13,14}$

Table I Study characteristics of published in regional cohort and national samples of methods of delivery

\begin{tabular}{|c|c|c|c|c|c|}
\hline Author & Year & $\mathbf{N}$ & Country & Clinical Variables Studied & Socio-Demographic variables \\
\hline Chanrachakul et al. ${ }^{15}$ & 2000 & $1,073,403$ & Thailand & Type of Delivery, indications & -- \\
\hline Murray et al. & 2000 & 540 & Chile & Type of Delivery, indications & -- \\
\hline Diógenes et al. ${ }^{16}$ & 2001 & 86,120 & Brazil & Type of Delivery, indications & -- \\
\hline Leung et al. ${ }^{21}$ & 2001 & 50,016 & China & Type of Delivery, Indications & Age, Education \\
\hline Potter et al. ${ }^{7}$ & 2001 & 1,136 & Brazil & $\begin{array}{l}\text { Previous Deliveries, Number of } \\
\text { antenatal visit, Preferred Delivery }\end{array}$ & Age, Education, Marital status \\
\hline Sreevidya et al..$^{18}$ & 2003 & 789 & India & $\begin{array}{l}\text { Type of Delivery, Indications, Number } \\
\text { of child }\end{array}$ & Age, Education \\
\hline Khawaja et al. ${ }^{8}$ & 2004 & 40,216 & Egypt & $\begin{array}{l}\text { Type of Delivery, Obstetric and, New } \\
\text { born characteristics }\end{array}$ & $\begin{array}{l}\text { Age, Education, Residence, Age of } \\
\text { Marriage }\end{array}$ \\
\hline Villar et al.' & 2006 & 97,095 & $\begin{array}{l}\text { Argentina, } \\
\text { Brazil, Cuba, } \\
\text { Ecuador, } \\
\text { México, } \\
\text { Nicaragua, } \\
\text { Paraguay and } \\
\text { Perú }\end{array}$ & $\begin{array}{l}\text { Parity, prior neonatal Death, Cesarean } \\
\text { previous, Anesthesia, Indications }\end{array}$ & Age, Marital status \\
\hline Alimohammadian et al. & 2007 & 824 & Iran & Infertility, Type of Delivery & $\begin{array}{l}\text { Age, marital status, Education, Economic } \\
\text { status }\end{array}$ \\
\hline Sueli de Almeida et al. & 2008 & 5,800 & Brazil & Parity & Age, Origin, Education \\
\hline Ahmad-Nia et al. & 2009 & 17991 & Iran & Typo of Delivery & Age, Education, Residence \\
\hline Rebelo et al. ${ }^{13}$ & 2010 & 5,035 & Brazil & Type of Delivery, Obstetric history & Age, Economic status, Residence \\
\hline Mendoza-Sassi et al." & 2010 & 2,557 & Brazil & $\begin{array}{l}\text { Type of Delivery, Obstetric history, and } \\
\text { Newborn characteristics }\end{array}$ & $\begin{array}{l}\text { Age, Skin color, Education, Economic and } \\
\text { Marital status }\end{array}$ \\
\hline Kuei-hui Chu et al. ${ }^{17}$ & 2010 & 473 & Taiwan & $\begin{array}{l}\text { Parity, abortion, Type of Delivery, } \\
\text { Clinical history, age, health problems } \\
\text { during Pregnancy }\end{array}$ & Age, Marital status, Work status \\
\hline Fesseha et al. ${ }^{9}$ & 2011 & 17,145 & Ethiopia & $\begin{array}{l}\text { Indications, Results after cesarean, Days } \\
\text { in hospital, Infections }\end{array}$ & Type of Institution \\
\hline Márquez-Calderón et al..$^{20}$ & 2011 & 293,558 & Spain & $\begin{array}{l}\text { Type of Delivery, Complications in the } \\
\text { Newborn, Newborn characteristics }\end{array}$ & Age, Education, Origin, marital status \\
\hline
\end{tabular}


Table Continues...

\begin{tabular}{|c|c|c|c|c|c|}
\hline Author & Year & $\mathbf{N}$ & Country & Clinical Variables Studied & Socio-Demographic variables \\
\hline Ghotbi et al. ${ }^{10}$ & 2012 & 600 & Iran & Typo of Delivery & $\begin{array}{l}\text { Age, Age of marriage, Husband's age, Rate } \\
\text { of House wife mothers, Husband's job, } \\
\text { Insurance, Education economic status }\end{array}$ \\
\hline Suárez-López et al. & 2013 & 2,469 & Mexico & $\begin{array}{l}\text { Type of Delivery, parity, Abortions, } \\
\text { Month of first consultation, Birth } \\
\text { weight baby }\end{array}$ & Age, Education, Residence. \\
\hline Redondo et al. ${ }^{14}$ & 2013 & 111 & Spain & Type of Delivery & Age \\
\hline Barros et al..$^{19}$ & 2013 & 4126 & Brazil & Obstetric History, Prenatal care & Economic level, Maternal Lifestyle. \\
\hline Hopkins et al. ${ }^{12}$ & 2014 & 12,586 & Brazil & $\begin{array}{l}\text { Give birth order,Type of hospital in } \\
\text { which the Delivery took place }\end{array}$ & Age, Education, Residence \\
\hline Soto-Vega et al. & 2015 & 504 & Mexico & $\begin{array}{l}\text { Gestational age, Indication, Fetal } \\
\text { presentation }\end{array}$ & Age, Economic status, Education \\
\hline
\end{tabular}

Table 2 Differences of cesarean section prevalence between public and private hospitals (CSRa is the global rate)

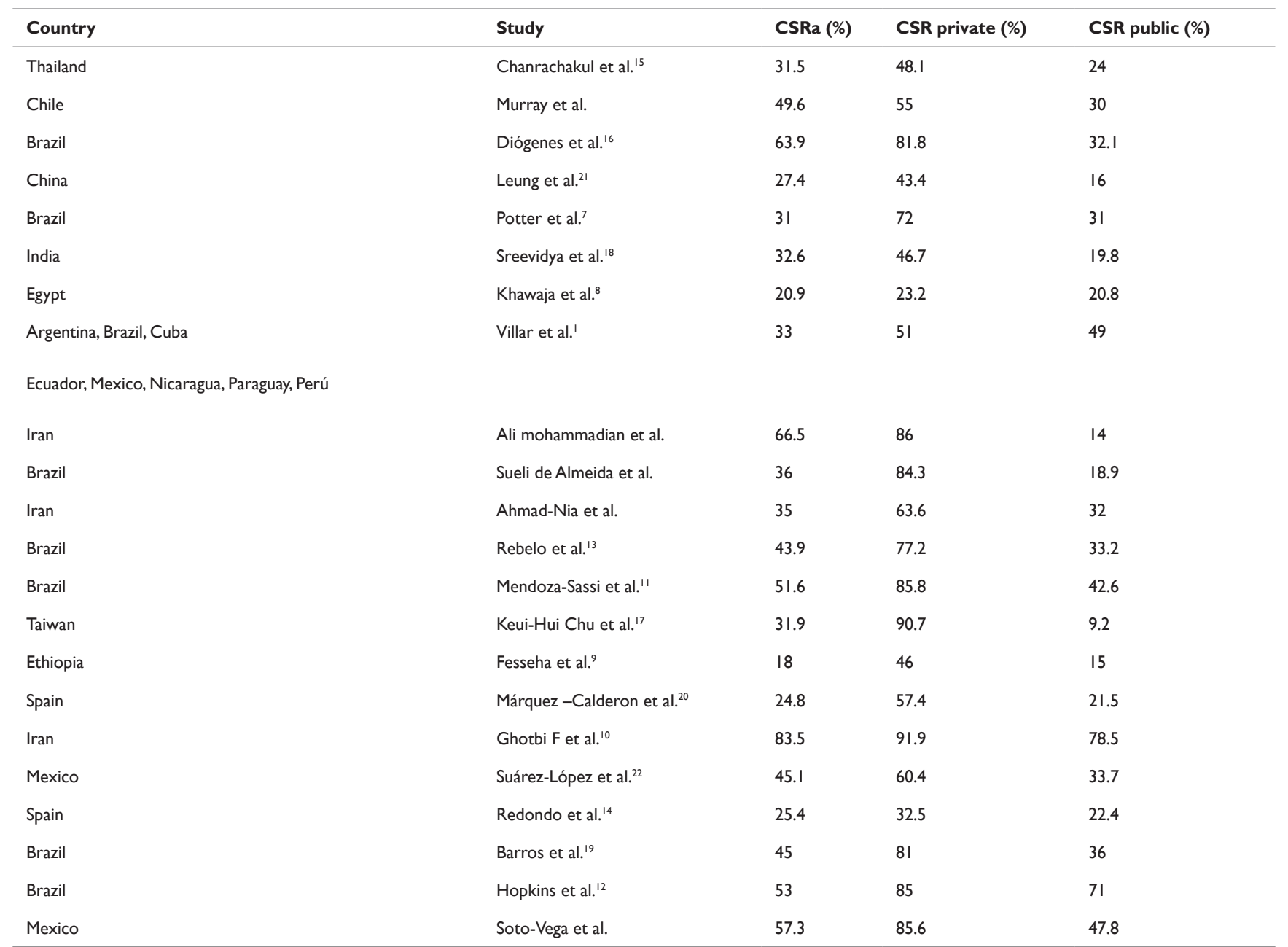

Table 3 Relationship between age and cesarean prevalence by ranges

\begin{tabular}{|c|c|c|c|c|c|c|c|c|c|c|c|}
\hline Age Range & $\begin{array}{l}\text { Sreevidya } \\
\text { et al. }{ }^{18}\end{array}$ & $\begin{array}{l}\text { Mendoza- } \\
\text { Sassi et } \\
\text { al." }\end{array}$ & $\begin{array}{l}\text { Márquez- } \\
\text { Calderon } \\
\text { et al. }{ }^{20}\end{array}$ & $\begin{array}{l}\text { Sueli de } \\
\text { Almeida } \\
\text { et al. }\end{array}$ & $\begin{array}{l}\text { Ahmad- } \\
\text { Nia et al. }\end{array}$ & $\begin{array}{l}\text { Rebelo } \\
\text { et al. }{ }^{13}\end{array}$ & $\begin{array}{l}\text { Kuei-hui } \\
\text { Chu et } \\
\text { al. }{ }^{17}\end{array}$ & $\begin{array}{l}\text { Suárez- } \\
\text { López } \\
\text { et al. }{ }^{22}\end{array}$ & $\begin{array}{l}\text { Redondo } \\
\text { et al. }{ }^{14}\end{array}$ & $\begin{array}{l}\text { Hopkins } \\
\text { et al. }{ }^{12}\end{array}$ & $\begin{array}{l}\text { Soto- } \\
\text { Vega et } \\
\text { al. }\end{array}$ \\
\hline$<20$ years & $20 \%$ & $15.60 \%$ & $16.70 \%$ & $46.70 \%$ & 21.25 & 31.2 & & $37.50 \%$ & - & $40.40 \%$ & $32.50 \%$ \\
\hline $20-30$ years & $29 \%$ & $26.30 \%$ & $22.30 \%$ & $51 \%$ & 26.85 & 40.12 & 25.49 & $44.90 \%$ & $28.10 \%$ & $50 \%$ & $55 \%$ \\
\hline $30-40$ years & $40 \%$ & $31.70 \%$ & $26.40 \%$ & $56.80 \%$ & 29.59 & 60.2 & 36.12 & $55.10 \%$ & - & $65.70 \%$ & $82.50 \%$ \\
\hline$>40$ years & - & - & $30.40 \%$ & - & 27.96 & & 66.6 & - & - & - & $85 \%$ \\
\hline
\end{tabular}

Citation:Vega ES, Casco S, Chamizo K, et al. Rising trends of cesarean section worldwide: a systematic review. Obstet Gynecol Int J. 20 I 5;3(2):260-265. 


\section{Which are the major indications for CS?}

The CS indications are important because of the risks involved; therefore a precise justification is necessary for its realization. Only seven articles reported the principal indication of a CS. In the studies reviewed, the most frequently reported cesarean indications were; cephalopelvic disproportion (CPD), fetal distress, prior cesarean, dysfunctional labor and elective cesarean. Among these indications, the majority of them are maternal indications and only one represents a fetal indication. The analysis of the articles revealed that the most mentioned is the CPD, but it is not the most frequent indication, The indications are different among countries and the health sector analyzed, for example Chanrachakul et al. ${ }^{15}$ showed that in Thailand a previous cesarean was the most prevalent indication in private hospitals (63\%), followed by failure to progress $(22 \%)$ in the public sector. Otherwise a study in México, established that the main indication in both sectors were previous CS with a prevalence of $40.8 \%$ in private and 38.5 in public (Soto-Vega et al.). Fetal distress was the prior indication in the private sector $(9.5 \%)$ and $(9 \%)$ in a public one; the second most frequent cause was CPD with $5.8 \%$ and $3.9 \%$ respectively. ${ }^{16}$ Taiwan presented the following indications: malpresentation (28.1\%), prior cesarean delivery (28.1\%), dysfunctional labor (26.4\%) and fetal distress $(8.3 \%) .{ }^{17}$ It was established in Ethiopia, CPD (34\%) as the main indication, followed by fetal distress $(15 \%)$ and with $(14 \%)$ breech/multiple gestations or abnormal presentation. ${ }^{9}$

\section{The Educational level is an important factor for the CS decision?}

Maternal scholar degree was considered as a factor associated with the election of the delivery method in this systematical review. The trend among some studies reviewed show a direct proportional relationship between cesarean section and a higher educational level. This gradient could be seen from different points of view. It could be translated as unequal social order (less access to a necessary intervention in the lower educational levels). For example a study conducted in India, suggested that $54 \%$ of women with \pm 10 years or of education had CS with an odds ratio of 3.4 and an adjusted odds ratio of 1.6 with $95 \%$ confidence interval. ${ }^{18}$ In Brazil women with higher maternal educational level ( \pm 12 years), showed a cesarean prevalence of $77.2 \% .{ }^{19}$ In Spain, $27.7 \%$ of women with a master's degree preferred $\mathrm{CS}^{20} \mathrm{An}$ article in China studied that women with a college degree preferred a cesarean delivery $(35 \%) .{ }^{21}$ In Iran was reported that mothers who had a higher education level requested CS more often ( $5 \%$ illiterate, $55.3 \%$ of those with a high school diploma and $76.3 \%$ of university educated women, $\mathrm{p}<0.0001) .{ }^{10}$ In Mexico it was found that $93.3 \%$ of the mothers with a $\mathrm{PhD}$ or a master degree, elected CS (Soto-Vega et al.). The results of these studies demonstrate that the chance of CS increases significantly as the scholar degree increase.

\section{Does socioeconomic level influences in the higher prevalence of CS?}

Frequently, the differences in maternal health access are more pronounced in different socioeconomic groups within each country. However, the socioeconomic factors that influence the access to specialized obstetric care hospitals are not well known. In this review was assessing whether the socioeconomic level is associated with the realization of cesarean section. Our research observed that two studies, in México, correlated the mode of delivery with the socioeconomic level of the pregnant women. It was established that belonging to high socioeconomic level was associated with $44 \%$ more chance of cesarean regarding low stratum $(\mathrm{OR}=1.44,95 \% \mathrm{CI}: 1.12-1.83) .{ }^{22} \mathrm{In}$ Mexico, it was concluded that women within the medium and high social classes were attend only in private hospitals and $85.07 \%$ of these women underwent to a CS (Soto-Vega et al.). A study carried out in Brazil, demonstrate that women attended in public hospitals had lower per capita family income, with a $49.5 \%$, representing $<1 / 2$ of the minimum wage. Even though this article didn't make a direct relationship between the family income and the mode of delivery, it was stated in the study that the majority of women having cesarean section were attended in private facilities. ${ }^{11}$

Ahmad Nia showed that in Iran the cesarean rate in economically active women was significantly higher than in non-active women in urban areas $(\mathrm{p} \leq 0.01)$, also in Iran studied that the higher husband's income level was associated with an increase in request for CS.

\section{Discussion}

The excessive use of CS is a serious problem worldwide. In the last decades it has been an increase in the CS practice. The increased number of CS realized is a multifactorial problem, concerning the institutional practices, the physician, social women characteristics and their environment. This systematic review demonstrates an overwhelming prevalence of CS, compared with the stipulated in the WHO, with a mean of $42.5 \%$ worldwide. Only one article of Ethiopia, Fesseha et al. ${ }^{9}$ established a prevalence of $18 \%$ of CS.

In the last fifteen years, several studies indicated that this surgical intervention has been increased, particularly in the private sector. The results of this analysis determine that the rate of cesarean delivery was higher at the private hospitals than in the public ones, reaching an alarming percentage, because most of the times the indication of the surgical procedure is not justified. The principal indication for CS in the articles analyzed was CPD. Even though, this observation could provide medical criteria indication for CS, but not all of the studies examined mention this indication as the first one. Which demonstrates that there are other factors that contribute to the CS prevalence?

Another factor observed among the studies reviewed was the age of the mother. Though the majority of the articles, the age represents an important factor associated with CS. The bigger CS rate is between 30 to 40 years old, with a mean of $51.17 \%$. Two articles reported an age range over 40 years, in which CS in Spain had a prevalence of $30.4 \%,{ }^{20}$ and in Mexico a prevalence of $85 \%$.

Also is important to notice the positive direct relationship between educational level and CS rates, which correlates with mother age, it has been demonstrated that women with more studies postpone the maternity.

The socio-economical level influences the health sector where women are attended; generally women with economic resources prefer to be attended at a private hospital. As a limitation of our review, it is important to establish that the population studied in the different articles was not homogenous. Therefore, when we extrapolated the results of the each study, it was difficult to obtain means and ranges groups for every category. There was only one variable consistent in every article reviewed that was the prevalence of CS in public and private hospitals, being the main objective of this revision.

\section{Conclusion}

This review considered five specific variables that influenced in the prevalence of CS. The principal variable analyzed, and also one of 
the main objectives of our study was the difference in CS prevalence, between private and public hospitals. As well, we analyzed age of the mother, cesarean indication, educational level and socioeconomic level. There are other variables that could be analyzed such as the CS prevalence in first pregnancy, the type of health insurance that the mother had and the place of residence. Nevertheless, we considered the most constant variables through the studies reviewed.

The importance of this review resides in the fact that the outcomes considered eighteen countries around the world, which can predict, an estimated of the global situation about the exaggerated prevalence of CS. Our review highlights the need to regulate the quantity of CS performed in hospitals, to reduce health costs and maternal and fetal risks. This findings also provides strong evidence that CS prevalence is markedly high around the world, especially in the private sector, that clearly demonstrate that there are other factors involved in this group of users.

\section{Acknowledgments}

None.

\section{Conflicts of interest}

The authors declare there is no conflict of interests.

\section{References}

1. Villar J, Valladares E, Wojdyla D, et al. Caesarean delivery rates and pregnancy outcomes: The 2005 WHO global survey on maternal and perinatal health in Latin America. Lancet. 2006;367(9525):1819-1829.

2. Althabe F, Sosa C, Belizán JM, et al. Cesarean section rates and maternal and neonatal mortality in low-, medium-, and high- income countries: an ecological study. Birth. 2006;33(4):270-277.

3. Declercq E, Barger M, Cabral HJ, et al. Maternal outcomes associated with planned primary cesarean births compared with planned vaginal births. Obstet Gynecol. 2007;109(3):669-677.

4. Declercq E, Cunningham DK, Johnson C, et al. Mothers' reports of postpartum pain associated with vaginal and cesarean deliveries: Results of a national survey. Birth. 2008;35(1):16-24.

5. Deneux-Tharaux C, Carmona E, Bouvier-Colle MH, et al. Postpartum maternal mortality and cesarean delivery. Obstet Gynecol. 2006;108(3):541-548.

6. World Health Organization. World Health Statistics. Italy; 2013.

7. Potter JE, Berquó E, Perpétuo IH, et al. Unwanted caesarean section among public and private patients in Brazil: Prospective study. BMJ. 2001;323:1155-1158.
8. Khawaja M, Jurdi R, Kabakian-Khasholian T. Rising Trends in Cesarean Section Rates in Egypt. Birth. 2004;31(1):12-16.

9. Fesseha N, Getachew A, Hiluf M, et al. A national review of cesarean delivery in Ethiopia. Int J Gynaecol Obstet. 2011;115(1):106-111.

10. Ghotbi F, Akbari Sene A, Azargashb E, et al. Women's knowledge and attitude towards mode of delivery and frequency of cesarean section on mother's request in six public and private hospitals in Tehran, Iran, 2012. J Obstet Gynaecol Res. 2014;40(5):1257-1266.

11. Mendoza-Sassi RA, Cesar JA, Silva PR, et al. Risk factors for cesarean section by category of health service. Rev Saude Publica. 2010;44(1):80 89.

12. Hopkins K, de Lima Amaral EF, Mouräo AN. The impact of payment source and hospital type on rising cesarean section rates in Brazil, 1998 to 2008. Birth. 2014;41(2):169-177.

13. Rebelo F, da Rocha CM, Cortes TR, et al. High cesarean prevalence in a national population- based study in Brazil: the role of private practice. Acta Obstet Gynecol Scand. 2010;89(7):903-908.

14. Redondo A, Sáez M, Oliva P, et al. Variabilidad en el porcentaje de cesáreas y en los motivos para realizarlas en los hospitales españoles. Gac Sanit. 2013;27(3):258-262.

15. Chanrachakul B, Herabutya Y, Udomsubpayakul U. Epidemic of Cesarean Section at the General, Private and University Hospitals in Thailand. J Obstet Gynaecol Res. 2000;26(5):357-361.

16. Diógenes M, Yazlle J, Mendes M, et al. Incidence of cesarean delivery regarding the financial support source for delivery care. Rev Saúde Pública. 2001;35(2):202-206.

17. Kuei-Hui C, Chen-Jei T, Chun-Sen H, et al. Women's preference for cesarean delivery and differences between Taiwanese women undergoing different modes of delivery. BMC Health Serv Res. 2010;10:138.

18. Sreevidya S, Sathiyasekaran B. High caesarean rates in Madras (India): a population-based cross sectional study. BJOG. 2003;110(2):106-111.

19. Barros F, Matijasevich A, Hallal PC, et al. Cesarean section and risk of obesity in childhood, adolescence, and early adulthood: evidence from 3 Brazilian birth cohorts. Am J Clin Nutr. 2012;95(2):465-470.

20. Márquez-Calderón S; Ruiz-Ramos M; Juárez S; et al. Caesarean delivery in Andalusia, Spain: relationship with social, clinical and health services factors (2007-2009). Rev Esp Salud Publica. 2011;85(2):205-215.

21. Pang MW, Lee TS, Leung AK, et al. A longitudinal observational study of preference for elective caesarean section among nulliparous Hong Kong Chinese women. BJOG. 2007;114(5):623-629.

22. Suarez-López, Campero L, De la Vara-Salazar E, et al. Sociodemographic and reproductive characteristics associated with the increase of cesarean section practice in Mexico. Salud Pública Mex. 2013;55(2):S225-S234. 